\title{
Apolipoprotein L1 Risk Genotypes in Ghanaian Systemic Lupus Erythematosus Patients: A Prospective Cohort Study
}

\author{
Ashira Blazer ( $\sim$ Ashira.Blazer@nyumc.org ) \\ NYU Langone Health https://orcid.org/0000-0002-0386-5259 \\ Ida Dzifa Dey \\ University of Ghana
}

Janet Nwaukoni

Philadelphia College of Osteopathic Medicine

Margret Reynolds

University of Ghana

\section{Festus Ankrah}

University of Ghana

\section{Huda Algasas}

Columbia University

\section{Tasneem Ahmed}

Robert Wood Johnson University Hospital

Jasmin Divers

New York University Long Island School of Medicine

\section{Research article}

Keywords: APOL1, Systemic Lupus Erythematosus, SLICC damage, West African, Lupus nephritis, Mortality

Posted Date: October 22nd, 2020

DOI: https://doi.org/10.21203/rs.3.rs-93715/v1

License: (c) (i) This work is licensed under a Creative Commons Attribution 4.0 International License. Read Full License

Version of Record: A version of this preprint was published at Lupus Science \& Medicine on January 1st, 2021. See the published version at https://doi.org/10.1136/lupus-2020-000460. 


\section{Abstract}

Objective: Two Apolipoprotein L1 (APOL 1) risk variants (RV) are enriched in sub-Saharan African populations due to a conferred resistance to Trypanosoma brucei. This comes at the cost of progressive renal disease by multiple causes including systemic lupus erythematosus (SLE). In African Americans, $A P O L 1$ high-risk genotypes have emerged as an important risk factor for progressive lupus nephritis. Despite emerging reports that SLE is common in Ghana, where APOL 1 variant allelic frequencies are high, the regional contribution to SLE outcomes has not been described. Accordingly, this prospective longitudinal cohort study tested the associations between APOL 1 high-risk genotypes and kidney outcomes, organ damage accrual, and death in 100 Ghanaian SLE patients.

Methods: A prospective cohort of 100 SLE outpatients met four 1982 American College of Rheumatology SLE criteria. Patients were assessed for demographics, SLE activity, and organ injury as measured by the Systemic Lupus International Collaborating Clinics Damage Index (SDI) at baseline and every 6 months for 1 year. Serum, plasma, and saliva samples were taken for serologic testing and APOL 1 genotyping. Outcomes of interest were kidney function, SDI, and case fatality.

Results: Assuming a recessive model of inheritance, the APOL 1 high-risk genotype (2RV) associated with developing end stage renal disease (ESRD) at an odds ratio of $14(p=0.008)$. These patients accrued more SDI points particularly in renal, neurologic, and cardio/pulmonary domains. The SDI was $81.3 \%$ higher in 2RV patients compared to ORV or $1 \mathrm{RV}$ patients despite no difference in SLE activity $(\mathrm{p}=0.02)$. After a 12 month period of observation, $3 / 12$ (25\%) of the 2RV patients died compared to $2 / 88(2.3 \%)$ of the $\mathrm{ORV}$ or $1 \mathrm{RV}$ carriers (odds ratio $=13.6, \mathrm{p}=0.01$ ). Deaths were due to end stage kidney disease and heart failure.

Conclusion: Our results suggest that in Ghanaian SLE patients, $A P O L 1$ risk variants are heritable risk factors for morbidity and mortality. Despite no appreciable differences in SLE severity, APOL 1 high-risk patients exhibited progressive renal disease, organ damage accrual, and a 13-fold higher case fatality rate.

\section{Key Messages}

- Ghanaian APOL 1 high-risk SLE patients exhibit early organ damage accrual and progressive kidney disease.

- APOL 1 high-risk genotypes do not associate with increased SLE activity.

- Ghanaian APOL 1 high-risk SLE patients showed a 13-fold higher case fatality rate.

\section{Introduction}

Two coding change variants in the Apolipoprotein L1 (APOL1) gene, G1 (S342G and I384M) and G2 (N388del;Y389del), have recently been identified in sub-Saharan African genomes. Some of the highest 
reported $A P O L 1$ variant allele frequencies can be found in Ghana, where up to $41 \%$ and $13 \%$ of alleles carry the $\mathrm{G} 1$ and $\mathrm{G} 2$ variants respectively (1). The variants are thought to have been evolutionarily conserved due to a protection against Trypanosoma brucei, the parasite cause of African trypanosomiasis (1). This infectious protection comes with a higher risk of several adverse phenotypes, including end stage renal disease (ESRD) by multiple causes and systemic lupus erythematosus (SLE) nephritis (2-4). Several epidemiologic studies on the African continent have linked APOL 1 to progressive renal disease, hypertension, and stroke; however no study has been performed in SLE (5-9).

SLE may represent an important context under which $A P O L 1$ variants confer heightened risk.

Associations between adverse phenotypes and $A P O L 1$ high-risk genotypes, defined as two variants in any combination (G1/G1, G1/G2, or G2/G2), are highly heterogeneous. For example the odds of developing chronic kidney disease range from 1.5-2.0 in otherwise healthy individuals, to 2.5-7.3 in SLE nephritis, to 29-80 in HIV-associated nephropathy (10-12). In SLE, the APOL 1 high-risk genotype has been shown to associate with collapsing glomerulopathy and progression to $\operatorname{ESRD}(2,12)$. Even carrying a single variant copy has been associated with hypertension, prevalent cardiovascular disease, and kidney injury in SLE $(13,14)$. One hypothesis for this is that gene penetrance is contingent upon environmental "second hits" (15).

Consistent with its immune function, $A P O L 1$ expression is highly responsive to inflammatory signals (16). We and others have shown that a wide range of stimuli, including endogenous and exogenous interferons, autoantigens, and SLE serum, increase APOL 1 expression and therefore intracellular accumulation $(16,17)$. APOL 1 contains both a $\mathrm{BH} 3$ domain that participates in the cellular stress response through autophagy, and a pore forming domain that can traverse phospholipid bilayers in a pHdependent fashion $(18,19)$. At high expression levels, intracellularly accumulated $A P O L 1$ shifts from a pro-autophagic function toward a cytotoxic pore forming function $(18,20)$. Pore formation has been shown to cause injury in kidney and vascular related cells including podocytes and endothelial cells.

Recent literature reports that severe SLE is more common in Ghana than previously appreciated. For example, a retrospective review showed that SLE represented 5.28/1000 inpatient admissions at Korle bu Teaching Hospital in Accra, Ghana (21). These patients experienced high mortality as $43 \%$ died, most commonly of kidney disease, over a two-year period (22). It is unclear how APOL 1 high-risk genotype contributes to this trend. We therefore conducted a prospective cohort study comparing outcomes across APOL 1 genotype groups in SLE patients seeking care at Korle bu Teaching Hospital in Accra, Ghana.

\section{Methods}

\section{Study Population:}

This prospective cohort study was compliant with the Declaration of Helsinki and approved by the Institutional Review Boards of the University of Ghana School of Medicine and Korle bu Teaching Hospital in Accra, Ghana prior to initiation. Enrollment was initiated at Korle bu Teaching Hospital outpatient rheumatology clinics between 2015 and 2017. All patients provided informed consent prior to 
enrollment. A consecutive sample of 100 individuals seeking clinical rheumatology care was invited to participate. Inclusion criteria were as follows: 1) $\geq 18$ years of age, 2) self-reported Ghanaian ancestry, and 3) fulfilling at least four 1982 American College of Rheumatology (ACR) criteria for SLE (23). Patients who were unwilling or unable to sign consent were excluded.

\section{Data Collection:}

Initial Enrollment. Each study participant completed a survey to assess demographics, medication lists, and ACR SLE criteria. The Systemic Lupus International Collaborating Clinics (SLICC) damage index and SLE activity index using the modified clinical SELENA-SLEDAI was taken during a routine clinical visit (24, 25). Complete physical examination, vital signs, and anthropometric measurements were recorded. SLE serologic results including anti-nuclear antibodies (ANA), anti-double stranded DNA antibodies (dsDNA), anti-SSA/Ro antibodies (Ro), anti-SSB/La antibodies (La), anti-smith antibodies (smith), anti-U1/RNP antibodies (RNP), and antiphospholipid antibodies (APS) were recorded. Baseline urine samples were evaluated by dipstick and urinalysis where available (Acon Laboratories Inc, San Diego CA), and saliva and whole blood were collected for DNA extraction (Oragene saliva collection kits DNA Genotek, Ottawa, Ontario, Canada) and serum and plasma (Becton, Dickinson and Company, Franklin Lakes, NJ, USA), respectively. Serum, plasma, and saliva samples were dated, batched, and shipped to the New York University (NYU) laboratory for processing.

Follow up: Each patient was followed longitudinally at 6-month intervals for 1 year. During follow up visits, physical exams, SELENA-SLEDAl, laboratory review, and medication lists were recorded. Serum, plasma, and urine dipstick were again taken or recorded.

\section{Sample Assessment}

Apolipoprotein L1 Genotyping: Study patients' genomic DNA was isolated from saliva using Oragene reagents according to the manufacturer's instructions (DNA Genotek, Ottawa, Ontario, Canada). As described previously, DNA isolates were stored at $-80^{\circ} \mathrm{C}$, and quantitated using a Nanodrop- 1000 spectrophotometer (Nanodrop Products, Wilmington, DE). DNA templates (100ng) were used for conventional polymerase chain reaction (PCR) as previously described (14). A single 300-base pair DNA segment containing the $A P O L 1$ gene, including reference $\mathrm{G} 0$ allele and polymorphisms $\mathrm{G} 1$ (rs73885319 and rs60910145) and G2 (rs71785313), was amplified using ApliTaq Gold 360 DNA Polymerase (Applied Biosystems, Foster City, CA). For quality control, DNA was elongated in both forward and reverse directions. Genotypes were analyzed using the Genewiz online platform as previously described (14).

Autoantibody Serologic Screening: Batched and shipped serum samples were screened for ANAs using the BioPlex ${ }^{\mathrm{TM}} 220$ ANA Screen in the NYU Langone Hospitals clinical lab. This automated system utilizes multiplex technology to measure 13 antibodies including SLE-relevant antigens dsDNA, chromatin, RNP$68 \mathrm{kDa}$, SSA-52 kDa, SSA-60 kDa, and Sm/RNP as described (26). A mixture of antigen-coated beads was combined with patient sample and diluent for an incubation period of 20 minutes at $37^{\circ} \mathrm{C}$. Beads were washed and treated with anti-human IgG antibody conjugated to phycoerthrin (PE) dye for a 10-minute 
incubation. Excess conjugate was removed, and the mixture was passed through a detector. The bead type and amount detected were read and reported.

\section{Statistical Analysis}

To test the association between APOL 1 genotype and SLE outcomes, we treated APOL 1 genotype as the predictive variable (coded Number_Alleles) and composite SLICC damage index (SDI), renal function, and case fatality as outcome variables (coded SLICC, Renal, and Mort, respectively). The associations between primary predictor and outcome variables were tested using Poisson regression for the SLICC damage and generalized estimation equations (GEE) to identify factors associated with the composite renal function measure overtime. The distribution of sex, age, SELENA-SLEDAI score, disease duration, kidney function and SLE criteria were assessed across genotype. Factors that associated with the outcome variables at a significance level less than 0.10 were treated as co-variates; they included the clinical SELENA-SLEDAI score, disease duration, and a renal function composite score obtained by performing a factor analysis of mean arterial pressure, eGFR, and proteinuria on urine dipstick followed by a varimax rotation $(27,28)$. The factor analysis was performed using data from the first visit. The eigenvector and the rotation matrix from this analysis was then used to derive the composite scores at the second and third visit.

Complete case and analyses are presented as the primary result; however, given the high rates of missing data, especially at the third visit, results from analyses using multiple imputations are also presented. Multiple imputation was performed assuming missing at random and monotone missingness. Results from the imputed datasets were combined using Rubin's approach as implemented in the SAS v9.4 MIANALYZE procedure $(29,30)$. Analyses were performed using R 3.6.3 or SAS version 9.4.

\section{Results}

\section{Characteristics of the Cohort}

We enrolled 100 outpatients who met inclusion criteria and were consented to participate at Korle bu Teaching Hospital in Accra, Ghana during their routine clinical care. Demographic characteristics are shown in Table 1. The mean \pm standard deviation (SD) age was $32 \pm 9.4$ years and $99 \%$ of the patients self-identified as female. The most common ethnic groups were Akan (42\%) followed by Ewe (28\%) and $\mathrm{Ga}(20 \%)$ representing $90 \%$ of the study participants. 
Table 1

Characteristics of the Study Population

\begin{tabular}{|c|c|c|c|c|c|}
\hline & \multicolumn{3}{|l|}{ Genotype } & \multirow{3}{*}{$\begin{array}{l}p \\
\text { value }\end{array}$} & \multirow{3}{*}{$\begin{array}{l}\text { Total } \\
(n=100)\end{array}$} \\
\hline & O RV & $1 \mathrm{RV}$ & $2 \mathrm{RV}$ & & \\
\hline & $(\mathrm{N}=38)$ & $(N=50)$ & $(N=12)$ & & \\
\hline \multicolumn{6}{|l|}{ Demographics } \\
\hline Age (years) & $\begin{array}{l}32.3 \pm \\
10.5\end{array}$ & $32.5 \pm 8.8$ & $\begin{array}{l}31.9 \pm \\
8.7\end{array}$ & 0.2 & $\begin{array}{l}32.4 \pm \\
9.4\end{array}$ \\
\hline Gender (\% female) & 100 & 98 & 100 & 0.4 & 99 \\
\hline Disease duration (years) & $1.9 \pm 1.4$ & $2.5 \pm 2.9$ & $2.7 \pm 1.7$ & 0.3 & $2.3 \pm 2.3$ \\
\hline $\begin{array}{l}\text { Symptom Onset to Diagnosis } \\
\text { (months) }\end{array}$ & $6.1 \pm 13.6$ & $\begin{array}{l}11.5 \pm \\
18.4\end{array}$ & $2.7 \pm 5.3$ & 0.1 & $\begin{array}{l}8.5 \pm \\
15.8\end{array}$ \\
\hline \multicolumn{6}{|l|}{ SLE Clinical Criteria (\% Positive) } \\
\hline Malar Rash & 45 & 52 & 33 & 0.5 & 49 \\
\hline Discoid Rash & 45 & 36 & 33 & 0.7 & 41 \\
\hline Photosensitivity & 39 & 36 & 67 & 0.2 & 39 \\
\hline Mucosal Ulcers & 47 & 48 & 50 & 0.9 & 48 \\
\hline Arthritis & 82 & 68 & 100 & 0.04 & 77 \\
\hline Serositis & 55 & 52 & 41 & 0.7 & 50 \\
\hline Renal & 61 & 49 & 45 & 0.5 & 53 \\
\hline Neurologic & 18 & 12 & 0 & 0.2 & 13 \\
\hline Hematologic & 50 & 45 & 45 & 0.8 & 50 \\
\hline Immunologic & 85 & 71 & 63 & 0.2 & 76 \\
\hline ANA & 97 & 88 & 100 & 0.2 & 93 \\
\hline \multicolumn{6}{|l|}{ Serologic Markers (\%) } \\
\hline dsDNA & 73 & 65 & 27 & 0.02 & 63 \\
\hline Smith & 64 & 49 & 45 & 0.4 & 54 \\
\hline Ro & 48 & 62 & 36 & 0.2 & 53 \\
\hline La & 13 & 20 & 17 & 0.7 & 15 \\
\hline RNP & 71 & 56 & 82 & 0.2 & 65 \\
\hline
\end{tabular}




\begin{tabular}{|c|c|c|c|c|c|}
\hline & \multicolumn{3}{|l|}{ Genotype } & \multirow{3}{*}{${ }_{\text {value }}^{p}$} & \multirow{3}{*}{$\begin{array}{l}\text { Total } \\
(n=100)\end{array}$} \\
\hline & $0 \mathrm{RV}$ & $1 \mathrm{RV}$ & $2 \mathrm{RV}$ & & \\
\hline & $(N=38)$ & $(N=50)$ & $(N=12)$ & & \\
\hline \multicolumn{6}{|l|}{ Ancillary medications (\% taking) } \\
\hline Statin & 11 & 0 & 9 & 0.1 & 5 \\
\hline ASA & 0 & 2.1 & 0 & 0.8 & 1 \\
\hline ACE or ARB & 22.2 & 18.8 & 9.0 & 0.1 & 18.9 \\
\hline \multicolumn{6}{|l|}{ SLE medications } \\
\hline Average prednisolone dose (mg) & $11.5 \pm 8.1$ & $\begin{array}{l}14.4 \pm \\
11.4\end{array}$ & $\begin{array}{l}10.7 \pm \\
4.5\end{array}$ & 0.3 & $\begin{array}{l}12.8 \pm \\
9.6\end{array}$ \\
\hline Average HCQ dose (mg) & $339 \pm 125$ & $300 \pm 149$ & $\begin{array}{l}309 \pm \\
164\end{array}$ & 0.1 & 315 \\
\hline Methotrexate (\% taking) & 5.4 & 10.4 & 25 & 0.4 & 10.3 \\
\hline MMF (\% taking) & 5.6 & 4.2 & 0.0 & 0.4 & 4.2 \\
\hline AZA (\% taking) & 55.6 & 28.6 & 27.3 & 0.2 & 37.3 \\
\hline \multicolumn{6}{|c|}{$\begin{array}{l}\text { Data presented as number } \pm \text { standard deviation unless indicated as percentages. Serologic markers } \\
\text { are reported as percent of patients ever positive for the respective auto-antibodies; dsDNA = anti- } \\
\text { double stranded DNA antibodies, Smith }=\text { anti-Smith antibodies, Ro }=\text { anti-SSA/Ro }(52 \text { or } 60) \\
\text { antibodies, La }=\text { anti-SSB } / \text { La }(48) \text { antibodies, RNP }=\text { anti-U1RNP antibodies. } \mathrm{N}=\text { number, ASA }=\text { aspirin } \\
\text { ACE or ARB = Angiotensin-converting enzyme inhibitor, or Angiotensin II receptor blockers, HCQ = } \\
\text { Hydroxychloroquine, MMF = Mycophenolate Mofetil, AZA = Azathioprin }\end{array}$} \\
\hline
\end{tabular}

On average, patients had a disease duration of $2.3 \pm 2.3$ years at the baseline. The reported time from symptom development to diagnosis was $8.5 \pm 15.8$ months. The most common ACR criteria was arthritis (77\%), followed by lupus nephritis (53\%), serositis (50\%), and hematologic disorder (50\%; Table 1$)$. Of the cohort, $76 \%$ had ANAs completed for the purposes of clinical care with a median titer of 1:320 and a range from 1:40 - 1:5120. The remaining $24 \%$ were diagnosed clinically. Upon testing sera in the NYU clinical laboratory, $93 \%$ of patients were ANA positive. The most common autoantibodies were RNP, Smith, dsDNA, and Ro, which were positive in $65 \%, 56 \%, 56 \%$, and $54 \%$ of the cohort, respectively (Table 1). The most commonly utilized medications were glucocorticoids (92\%) and hydroxychloroquine (87\%). NSAID use was also common with $73 \%$ of the cohort taking these drugs at baseline survey. The most common disease modifying antirheumatic drugs (DMARDs) were azathioprine, cyclophosphamide, and methotrexate with $37 \%, 13 \%$, and $10 \%$ of patients receiving these drugs.

\section{APOL1 Genotype Associates with SLICC Damage Index}


The average SLICC Damage Index (SDI) was $1.1 \pm 1.5$ (mean \pm SD) at enrollment; $54 \%$ of the cohort had a non-zero SLICC damage index with on average 2.3 years of SLE disease duration on enrollment. The frequencies of the ancestral G0 and risk variant (RV) $\mathrm{G} 1$ or $\mathrm{G} 2$ allele were $0.64,0.21$, and 0.12 respectively, and the allele distribution did not deviate from Hardy Weinberg Equilibrium $(p=0.2$, Table 2$)$.

Table 2

Cohort Patients Ethnicities and APOL1 Allelic Frequencies

\begin{tabular}{|c|c|c|c|c|c|c|c|}
\hline & \multicolumn{7}{|l|}{ Genotype } \\
\hline & $0 \mathrm{RV}$ & $1 \mathrm{RV}$ & $2 \mathrm{RV}$ & \multicolumn{3}{|c|}{ Allele Frequency } & Total \\
\hline G0 & G1 & $\mathrm{G} 2$ & & & & & \\
\hline Ethnicity & N (\%) & N (\%) & $\mathrm{N}(\%)$ & & & & $\mathrm{N}(\%)$ \\
\hline Akan & 13 (33.3) & $23(46.0)$ & $6(50)$ & 0.58 & 0.25 & 0.17 & $42(42)$ \\
\hline $\mathrm{Ga}$ & $9(23.1)$ & $10(20.0)$ & $2(16.7)$ & 0.67 & 0.26 & 0.02 & $21(21)$ \\
\hline Ewe & $15(38.5)$ & $11(22.0)$ & $2(16.7)$ & 0.73 & 0.11 & 0.12 & $28(28)$ \\
\hline Northern Tribe & $1(2.6)$ & $5(10.0)$ & $1(8.3)$ & 0.56 & 0.38 & 0.06 & $8(8)$ \\
\hline Other & 0 & $1(2.0)$ & $1(8.3)$ & 0.25 & 0.50 & 0.25 & $2(2)$ \\
\hline Total & $38(100)$ & $50(100)$ & $12(100)$ & 0.64 & 0.24 & 0.12 & 100 \\
\hline
\end{tabular}

APOL 1 high-risk (2RV) patients exhibited higher SDI, compared to patients with zero or one variant (mean $\mathrm{SDI} O R V$ or $1 \mathrm{RV}=0.99 \pm 1.2$ vs $2 \mathrm{RV}=1.75 \pm 2.6, \mathrm{p}=0.1)$. $A P O L 1$ high-risk patients accrued more SDI points in renal, cardiac, and neurologic domains (Fig. 1). To model SDI points accrued by genotype, a Poisson regression with a logarithmic link was used (Table 3). In the unadjusted model, 2RV patients showed an $81.3 \%$ (95\% Cl: 12.3,192.7) higher SDI compared to APOL 1 low-risk (1RV or ORV) patients. In the first model adjusted for average SLEDAI score, the increase was $72.2 \%(95 \% \mathrm{Cl}: 6.5,178.3)$ among $2 \mathrm{RV}$ patients, relative to $\mathrm{ORV}$ or $1 \mathrm{RV}$ patients. An increase of one unit in the 12-month average SLEDAI score corresponded to a $4.7 \%(95 \% \mathrm{Cl}: 2.0,7.3 \%)$ increase in the SLICC damage score (Table 3). Further adjustment for disease duration in the third model did not change this result $(1.5 \%, 95 \% \mathrm{Cl}:-6.5,10.2)$. Unadjusted and adjusted model summaries including both complete case data and data with imputed values are shown in Table 3. 
Table 3

APOL1 Genotype Associates with SLICC Damage Index

Model

Observed data

Imputed Analysis

Percent change $(95 \% \mathrm{Cl}) \quad$ P-value Percent change $(95 \% \mathrm{Cl}) \quad$ P-value

Unadjusted Poisson Regression Model (recessive)

0 or $1 \mathrm{RV}$ vs $2 \mathrm{RV}$

$81.3(12.3,192.7)$

0.01

$78.4(10.6,187.8)$

0.02

Poisson Regression Model (recessive), adjusted for SLEDAI
0 or $1 \mathrm{RV}$ vs $2 \mathrm{RV}$
$72.2(6.5,178.3)$
0.03
$69.5(4.9,173.8)$
0.03
Average SLEDAI
$4.7(1.9,7.7)$
0.001
$4.7(1.8,7.6)$
0.001

Poisson Regression Model (recessive), adjusted for SLEDAl and duration of SLE
0 or $1 \mathrm{RV}$ vs $2 \mathrm{RV}$
$80.8(11,194.4)$
0.01
$77.7(9.2,189.1)$
0.02
Average SLEDAI
$4.2(1.1,7.4)$
0.008
$4.2(1.1,7.3)$
0.008
Disease Duration
$1.5(-6.5,10.2)$
0.72
$1.5(-6.5,10.1)$
0.73

Percent change (rate of change) and $95 \%$ confidence intervals $(95 \% \mathrm{Cl}$ ) for the unadjusted Poisson regression model, as well as two adjusted Poisson regression models are shown. Results are shown for the complete case analysis (observed data, excluding missing values) and following multiple imputations, assuming missing at random (Imputed Analysis). SLEDAI = Systemic Lupus Erythematosus Disease Activity Index.

\section{APOL1 Genotype is Associated with Renal Function}

A higher proportion of 2RV patients had $2+$ or greater proteinuria scores on urine dipstick at baseline, 6 months, and 12 months (Fig. 2A). These patients also exhibited higher mean arterial pressure (MAP) at each time point, and lower eGFR as measured by the CKD-EPI formula ( $p=0.01$ for each outcome MAP and eGFR; Fig. 2B and C). During the 12-month period, of the five patients who progressed to ESRD as defined by eGFR $\leq 15 \mathrm{ml} / \mathrm{min} / 1.73 \mathrm{~m}^{2}$ or referral for hemodialysis, three were $2 \mathrm{RV}$ carriers. Assuming a recessive mode of inheritance, carrying $2 \mathrm{RV}$ in $A P O L 1$ is associated with developing ESRD (OR $=14$ [95\% Cl: 2.1, 95.2]; $p=0.008)$.

To capture the effect of 2RV status on urine dipstick proteinuria, MAP, and lower eGFR, a weighted average of each variable was created to fully represent kidney function. This weighted average was designated as a composite variable called "factor one," which was proportional to kidney function and computed with the following loadings: factor one $=(-0.67 \times \mathrm{MAP})-(0.28 \mathrm{X}$ dipstick protein $)+(0.63 \mathrm{x}$ eGFR). In the GEE model, $A P O L 1$ variants associated with a decrease in the renal factor one $(-0.76,95 \%$ Cl: -1.35, -0.16). Upon controlling for SLICC damage index, this association between APOL 1 variants and factor one remained $(-0.63,95 \% \mathrm{Cl}:-1.1,-0.16)$. Lastly, this association was not mitigated by disease duration (Table 4). 
Table 4

APOL1 Genotype Associates with Renal Function

\begin{tabular}{|c|c|c|c|c|}
\hline \multirow[t]{2}{*}{ Model } & \multicolumn{2}{|l|}{ Observed data } & \multicolumn{2}{|l|}{ Imputed Analysis } \\
\hline & Estimate $(95 \% \mathrm{Cl})$ & P-value & Estimate $(95 \% \mathrm{Cl})$ & P-value \\
\hline \multicolumn{5}{|c|}{ Linear Regression Model (recessive) } \\
\hline $2 \mathrm{RV}$ vs 0 or $1 \mathrm{RV}$ & $-0.76(-1.35,-0.16)$ & 0.01 & $-0.73(-1.42,-0.04)$ & 0.04 \\
\hline \multicolumn{5}{|c|}{ Linear Regression Model (recessive) adjusted for SDI } \\
\hline $2 \mathrm{RV}$ vs 0 or $1 \mathrm{RV}$ & $-0.63(-1.1,-0.16)$ & 0.01 & $-0.6(-1.14,-0.05)$ & 0.03 \\
\hline SDI & $-0.17(-0.29,-0.04)$ & 0.01 & $-0.17(-0.31,-0.02)$ & 0.02 \\
\hline \multicolumn{5}{|c|}{ Linear Regression Model (recessive) adjusted for SDI and duration of SLE } \\
\hline $2 \mathrm{RV}$ vs 0 or $1 \mathrm{RV}$ & $-0.64(-1.12,-0.16)$ & 0.01 & $-0.61(-1.16,-0.06)$ & 0.03 \\
\hline SDI & $-0.18(-0.31,-0.05)$ & 0.01 & $-0.18(-0.33,-0.02)$ & 0.02 \\
\hline Disease Duration & $-0.05(-0.11,0.02)$ & 0.14 & $-0.05(-0.12,0.02)$ & 0.18 \\
\hline \multicolumn{5}{|c|}{$\begin{array}{l}\text { Table shows the association between APOL1 genotype and renal function as measured by a weighted } \\
\text { average of dipstick proteinuria, mean arterial pressure, and eGFR. Parameter estimates (Estimate) and } \\
95 \% \text { confidence intervals ( } 95 \% \mathrm{CI} \text { ) are presented for the unadjusted linear regression model with } \\
\text { generalized estimating equation (GEE) to account for repeated observations followed by adjustment } \\
\text { for SDI and duration of SLE. Models were fitted in the observed data, excluding missing observation } \\
\text { and imputed datasets, assuming missing at random. SDI = SLICC damage index. }\end{array}$} \\
\hline
\end{tabular}

\section{APOL1 Genotype is Associated with Case Fatality}

The case fatality rate was significantly higher in 2RV patients. Over 12 months, $2.3 \%$ (2 out of 88 ) patients with $0 \mathrm{RV}$ or $1 \mathrm{RV}$ died compared to $25 \%$ (3 out of 12) $2 \mathrm{RV}$ patients corresponding with an odds ratio of 13.6 (95\% Cl: 1.4,182.6). Deaths in the ORV or 1RV group were due to ESRD and sepsis during pregnancy. In the $2 \mathrm{RV}$ patients, deaths were due to ESRD and heart failure. Case fatality rate and causes of death are summarized in Figure 3. The association between the APOL 1 high-risk genotype and case fatality remained upon controlling for average SLEDAl at an odds ratio of 14.8 (95\% Cl: 2.0,109.4). Taken together, these data suggest that $A P O L 1$ high-risk genotype is a contributor to SLE mortality independent of disease activity.

\section{Discussion}

The central findings in our study were that carrying 2RV was associated with proteinuria, higher mean arterial pressure, and lower average eGFR levels despite similar SLE activity measures. Compared to the ORV and 1RV patients, the 2RV group accumulated more points on the SDI both in renal domains and in those suggesting microvascular disease including cognitive impairment, digital pulp loss, and panniculitis. The case fatality rate in $2 \mathrm{RV}$ carriers was 14.6 fold that of the $0 \mathrm{RV}$ or $1 \mathrm{RV}$ carriers upon controlling for SLE disease activity. Deaths in the 2RV patients were due to ESRD and heart failure, consistent with previously identified $A P O L 1$ variant-associated phenotypes. Importantly the $A P O L 1$ risk 
genotype correlated with SDI, renal progression, and case fatality independent of SLE disease activity, suggesting that in Ghanaian SLE patients, these variants may be significant prognostic indicators.

Associations between the $A P O L 1$ high-risk genotype and non-diabetic kidney disease by multiple causes have been consistent with recent reports of early-onset renal disease in West Africa $(2,3,6,10,31,32)$. Notably, reports from Ghana indicate that the $A P O L 1$ high-risk genotype is associated with small vessel ischemic stroke, a risk factor for cognitive impairment (9). In the United States, reports implicate the $A P O L 1$ high-risk genotype in extra-renal phenotypes including pre-eclampsia and non-diabetic microvascular stroke (33-35). The current study adds to the understanding of APOL 1 high-risk genotype manifestations in SLE. In addition to renal domains, 2RV patients accrued more damage due to cognitive impairment, pulmonary infection, and digital pulp loss. Kidney phenotypes are reportedly potentiated by comorbid infectious or inflammatory disease (16). SLE is an extremely heterogeneous disease, with variation in clinical manifestations, race and ethnicity, disease onset, medication requirements, and disease activity all contributing to morbidity and mortality $(24,36,37)$. Genetic susceptibility to early damage accrual, particularly in renal and cardiovascular domains, is implicated in early SLE deaths (38). Recently, a Swedish group found that a higher cumulative genetic risk score spanning 57 SLE-associated loci was implicated in SLE onset, severity, organ damage, and death; however, APOL 1 was not identified likely due to a lack of patients with African continental ancestry (38). The current study highlights the need to perform additional genetic susceptibility analyses in SLE patients of diverse ancestral backgrounds.

Several Sub-Saharan African case series have identified high SLE-related morbidity and mortality due to infections and cardio-renal disease $(21,22,39)$. While epidemiologic studies on the African continent are sparse, individuals of recent African ancestry throughout the diaspora have some of the highest reported incidence and prevalence of SLE $(40,41)$. This trend is compounded by higher morbidity and mortality due to renal, neurologic, and cardiovascular disease $(36,37,40,41)$. In the United States, SLE ranked among the top ten causes of death in African American women from the second through fifth decades of life (42). Moreover, African American SLE patients have demonstrably higher prevalent comorbid hypertensive, renal, and cardiovascular disease compared to their European American counterparts (43). Damage accrual on renal and cardiovascular domains of the SDI are independent risk factors for early SLE mortality (24). While many socioeconomic factors are at play, the observed association between these critical outcomes and $A P O L 1$ risk genotype in SLE may be an under-appreciated genetic contribution.

The current study is not without limitations. Given SLE disease heterogeneity, other genetic, treatment, and environmental factors contribute to damage accrual, kidney disease susceptibility, and mortality. This highlights the need for genome-wide association studies in a continental African SLE population. The generalizability of the findings is limited by the small sample size with $12 \%$ of participants in the $2 \mathrm{RV}$ group. Larger studies are necessary to better understand the associations between the APOL 1 polymorphisms and systemic disease. Patients were often unable to afford or obtain laboratory studies at each visit, thus limiting longitudinal laboratory data. This could have underestimated SLE activity 
based on available disease measures (44). In addition, high one-year mortality could be attributed to limited access to DMARDs and life-saving dialysis treatments. Study patients commonly used NSAIDs and corticosteroids both of which have adverse cardio-renal effects. However, this phenomenon influenced all study patients across genotype groups. Despite these limitations, this novel Sub-Saharan African study offers important information regarding APOL 1 risk phenotypes in SLE.

\section{Conclusion}

These data implicate APOL1 high-risk genotype in SLE renal progression, extra-renal damage accrual, and mortality. Further, we identify a potential genetic associations to high SLE-associated mortality in SubSaharan Africa. Additional research is required to determine the utility and cost-effectiveness of APOL 1 genotyping in SLE patients of recent African ancestry for risk stratification and disease prevention.

\section{Declarations}

\section{ETHICS APPROVAL AND CONSENT TO PARTICIPATE}

All study participants signed informed consent prior to participating in this study. Ethics approval was granted by The University of Ghana Ethics Board. This study was conducted in compliance with the Declaration of Helsinki.

\section{CONSENT FOR PUBLICAITON}

Not Applicable

\section{AVAILABILITY OF DATA AND MATERIALS}

The datasets generated during and/or analyzed during the current study are available from the corresponding author on reasonable request.

\section{COMPETING INTERESTS}

The authors declare no competing financial conflicts of interests.

\section{FUNDING}

This project was supported in part by the Rheumatology Research Foundation Scientist Development Award to A.B.; the National Center for the Advancement of Translational Science (NCATS) (KL2 1UL1TR001445) to A.B.; and The Judith \& Stewart Colton Center for Autoimmunity Scholar Award to A.B.

\section{AUTHORS' CONTRIBUTIONS}

Each author made substantial contributions to conception (AB, IDD, JN), data acquisition and analysis (AB, MR, FA, JD), and/or drafting the work (AB, HA, TA). In addition, all authors have approved the 
submitted version of this manuscript, and have agreed to be personally accountable for his or her own contributions.

\section{ACKNOWLEDGEMENTS}

The authors would like to acknowledge the Buyon/Clancy laboratory where genotyping work was completed for this project, and the advice of mentors and peers including Drs. Jill Buyon, Robert Clancy, Timothy Niewold, Greg Silverman, Janina Jeff, and Peter Izmirly.

\section{References}

1. Limou S, Nelson GW, Kopp JB, Winkler CA. APOL1 kidney risk alleles: population genetics and disease associations. Adv Chronic Kidney Dis. 2014;21(5):426-33.

2. Freedman BI, Langefeld CD, Andringa KK, Croker JA, Williams AH, Garner NE, et al. End-stage renal disease in African Americans with lupus nephritis is associated with APOL1. Arthritis Rheumatol. 2014;66(2):390-6.

3. Papeta N, Kiryluk K, Patel A, Sterken R, Kacak N, Snyder HJ, et al. APOL1 variants increase risk for FSGS and HIVAN but not IgA nephropathy. Journal of the American Society of Nephrology : JASN. 2011;22(11):1991-6.

4. Kruzel-Davila E, Wasser WG, Aviram S, Skorecki K. APOL1 nephropathy: from gene to mechanisms of kidney injury. Nephrol Dial Transplant. 2016;31(3):349-58.

5. Ko WY, Rajan P, Gomez F, Scheinfeldt L, An P, Winkler CA, et al. Identifying Darwinian selection acting on different human APOL1 variants among diverse African populations. Am J Hum Genet. 2013;93(1):54-66.

6. Ekulu PM, Nkoy AB, Betukumesu DK, Aloni MN, Makulo JRR, Sumaili EK, et al. APOL1 Risk Genotypes Are Associated With Early Kidney Damage in Children in Sub-Saharan Africa. Kidney Int Rep. 2019;4(7):930-8.

7. Sumaili EK, Shemer R, Kruzel-Davila E, Cohen EP, Mutantu PN, Bukabau JB, et al. G1 is the major APOL1 risk allele for hypertension-attributed nephropathy in Central Africa. Clin Kidney J. 2019;12(2):188-95.

8. Ulasi, II, Tzur S, Wasser WG, Shemer R, Kruzel E, Feigin E, et al. High population frequencies of APOL1 risk variants are associated with increased prevalence of non-diabetic chronic kidney disease in the Igbo people from south-eastern Nigeria. Nephron Clin Pract. 2013;123(1-2):123-8.

9. Akinyemi R, Tiwari HK, Arnett DK, Ovbiagele B, Irvin MR, Wahab K, et al. APOL1, CDKN2A/CDKN2B, and HDAC9 polymorphisms and small vessel ischemic stroke. Acta Neurol Scand. 2018;137(1):13341.

10. Parsa A, Kao WH, Xie D, Astor BC, Li M, Hsu CY, et al. APOL1 risk variants, race, and progression of chronic kidney disease. N Engl J Med. 2013;369(23):2183-96. 
11. Kopp JB, Nelson GW, Sampath K, Johnson RC, Genovese G, An P, et al. APOL1 genetic variants in focal segmental glomerulosclerosis and HIV-associated nephropathy. Journal of the American Society of Nephrology : JASN. 2011;22(11):2129-37.

12. Larsen CP, Beggs ML, Saeed M, Walker PD. Apolipoprotein L1 risk variants associate with systemic lupus erythematosus-associated collapsing glomerulopathy. J Am Soc Nephrol. 2013;24(5):722-5.

13. Vajgel G, Lima SC, Santana DJS, Oliveira CBL, Costa DMN, Hicks PJ, et al. Effect of a Single Apolipoprotein L1 Gene Nephropathy Variant on the Risk of Advanced Lupus Nephritis in Brazilians. J Rheumatol. 2020;47(8):1209-17.

14. Blazer A, Wang B, Simpson D, Kirchhoff T, Heffron S, Clancy RM, et al. Apolipoprotein L1 risk variants associate with prevalent atherosclerotic disease in African American systemic lupus erythematosus patients. PLoS One. 2017;12(8):e0182483.

15. Langefeld CD, Comeau ME, Ng MCY, Guan M, Dimitrov L, Mudgal P, et al. Genome-wide association studies suggest that APOL1-environment interactions more likely trigger kidney disease in African Americans with nondiabetic nephropathy than strong APOL1-second gene interactions. Kidney Int. 2018.

16. Nichols B, Jog P, Lee JH, Blackler D, Wilmot M, D'Agati V, et al. Innate immunity pathways regulate the nephropathy gene Apolipoprotein L1. Kidney Int. 2015;87(2):332-42.

17. Ashira Blazer SR, Androo Markham, Shilpi Mehta-Lee, Jill P. Buyon, and Robert M. Clancy. InterferonInduced APOL1 over-Expression Causes Autophagic Dysfunction and Mitochondrial Stress in Risk Variant-Carrying Endothelial Cells. Arthritis Rheumatol. 2017;69(10).

18. Vanhollebeke B, Pays E. The function of apolipoproteins L. Cell Mol Life Sci. 2006;63(17):1937-44.

19. Ma L, Divers J, Freedman BI. Mechanisms of Injury in APOL1-associated Kidney Disease. Transplantation. 2019;103(3):487-92.

20. Thomson R, Finkelstein A. Human trypanolytic factor APOL1 forms pH-gated cation-selective channels in planar lipid bilayers: relevance to trypanosome lysis. Proc Natl Acad Sci U S A. 2015;112(9):2894-9.

21. Dey IDB, Atiase Y, Yorke E, Ganu V, Mate-Kole C. C. Rheumatology in Ghana- A Paradigm Change. Internal Medicine Practice in Ghana: Challenges, Innovations, and Future Directions: Margaret Lartey, Timothy Archampong, and Michael O Mate-Kole; 2015. p. 7-21.

22. Dzifa D, Boima V, Yorke E, Yawson A, Ganu V, Mate-Kole C. Predictors and outcome of systemic lupus erythematosus (SLE) admission rates in a large teaching hospital in sub-Saharan Africa. Lupus. 2018;27(2):336-42.

23. Tan EM, Cohen AS, Fries JF, Masi AT, McShane DJ, Rothfield NF, et al. The 1982 revised criteria for the classification of systemic lupus erythematosus. Arthritis Rheum. 1982;25(11):1271-7.

24. Chambers SA, Allen E, Rahman A, Isenberg D. Damage and mortality in a group of British patients with systemic lupus erythematosus followed up for over 10 years. Rheumatology (Oxford). 2009;48(6):673-5. 
25. Petri M, Kim MY, Kalunian KC, Grossman J, Hahn BH, Sammaritano LR, et al. Combined oral contraceptives in women with systemic lupus erythematosus. N Engl J Med. 2005;353(24):2550-8.

26. Desplat-Jego S, Bardin N, Larida B, Sanmarco M. Evaluation of the BioPlex 2200 ANA screen for the detection of antinuclear antibodies and comparison with conventional methods. Ann N Y Acad Sci. 2007;1109:245-55.

27. Kaiser HF. The varimax criterion for analytic rotation in factor analysis. Psychometrika. 1958;23:187200.

28. Fabrigar LR, Wegener DT. Exploratory factor analysis. New York, NY, US: Oxford University Press; 2012. viii, 159-viii, p.

29. Rubin DB. Multiple Imputation after 18+ Years. Journal of the American Statistical Association. 1996;91(434):473-89.

30. RUBIN DB. Inference and missing data. Biometrika. 1976;63(3):581-92.

31. Woroniecki RP, Ng DK, Limou S, Winkler CA, Reidy KJ, Mitsnefes M, et al. Renal and Cardiovascular Morbidities Associated with APOL1 Status among African-American and Non-African-American Children with Focal Segmental Glomerulosclerosis. Front Pediatr. 2016;4:122.

32. Freedman BI, Kopp JB, Langefeld CD, Genovese G, Friedman DJ, Nelson GW, et al. The apolipoprotein L1 (APOL1) gene and nondiabetic nephropathy in African Americans. Journal of the American Society of Nephrology : JASN. 2010;21(9):1422-6.

33. Reidy KJ, Hjorten RC, Simpson CL, Rosenberg AZ, Rosenblum SD, Kovesdy CP, et al. Fetal-Not Maternal-APOL1 Genotype Associated with Risk for Preeclampsia in Those with African Ancestry. Am J Hum Genet. 2018;103(3):367-76.

34. Bruggeman LA, Wu Z, Luo L, Madhavan SM, Konieczkowski M, Drawz PE, et al. APOL1-G0 or APOL1G2 Transgenic Models Develop Preeclampsia but Not Kidney Disease. Journal of the American Society of Nephrology : JASN. 2016;27(12):3600-10.

35. Gutierrez OM, Irvin MR, Chaudhary NS, Cushman M, Zakai NA, David VA, et al. APOL1 Nephropathy Risk Variants and Incident Cardiovascular Disease Events in Community-Dwelling Black Adults. Circ Genom Precis Med. 2018;11(6):e002098.

36. Duran S, Gonzalez LA, Alarcon GS. Damage, accelerated atherosclerosis, and mortality in patients with systemic lupus erythematosus: lessons from LUMINA, a multiethnic US cohort. J Clin Rheumatol. 2007;13(6):350-3.

37. Petri M, Purvey S, Fang H, Magder LS. Predictors of organ damage in systemic lupus erythematosus: the Hopkins Lupus Cohort. Arthritis Rheum. 2012;64(12):4021-8.

38. Reid S, Alexsson A, Frodlund M, Morris D, Sandling JK, Bolin K, et al. High genetic risk score is associated with early disease onset, damage accrual and decreased survival in systemic lupus erythematosus. Ann Rheum Dis. 2020;79(3):363-9.

39. Adelowo OO, Umeizudike T, Olaosebikan H, Awobusuyi JO. Nephritis as an initial diagnosis of lupus in Nigerian patients. Afr J Med Med Sci. 2014;43(2):99-105. 
40. Izmirly PM, Wan I, Sahl S, Buyon JP, Belmont HM, Salmon JE, et al. The Incidence and Prevalence of Systemic Lupus Erythematosus in New York County (Manhattan), New York: The Manhattan Lupus Surveillance Program. Arthritis Rheumatol. 2017;69(10):2006-17.

41. Alarcon GS. Lessons from LUMINA: a multiethnic US cohort. Lupus. 2008;17(11):971-6.

42. Yen EY, Singh RR. Brief Report: Lupus-An Unrecognized Leading Cause of Death in Young Females: A Population-Based Study Using Nationwide Death Certificates, 2000-2015. Arthritis Rheumatol. 2018;70(8):1251-5.

43. Barnado A, Carroll RJ, Casey C, Wheless L, Denny JC, Crofford LJ. Phenome-wide association study identifies marked increased in burden of comorbidities in African Americans with systemic lupus erythematosus. Arthritis Res Ther. 2018;20(1):69.

44. Dey D. Juggling Art: Making Critical Clinical Decisions without Vital Laboratory Support in Autoimmune Rheumatic Patients in a Resource Poor Setting. Ghana Med J. 2017;51(2):47-9.

\section{Figures}




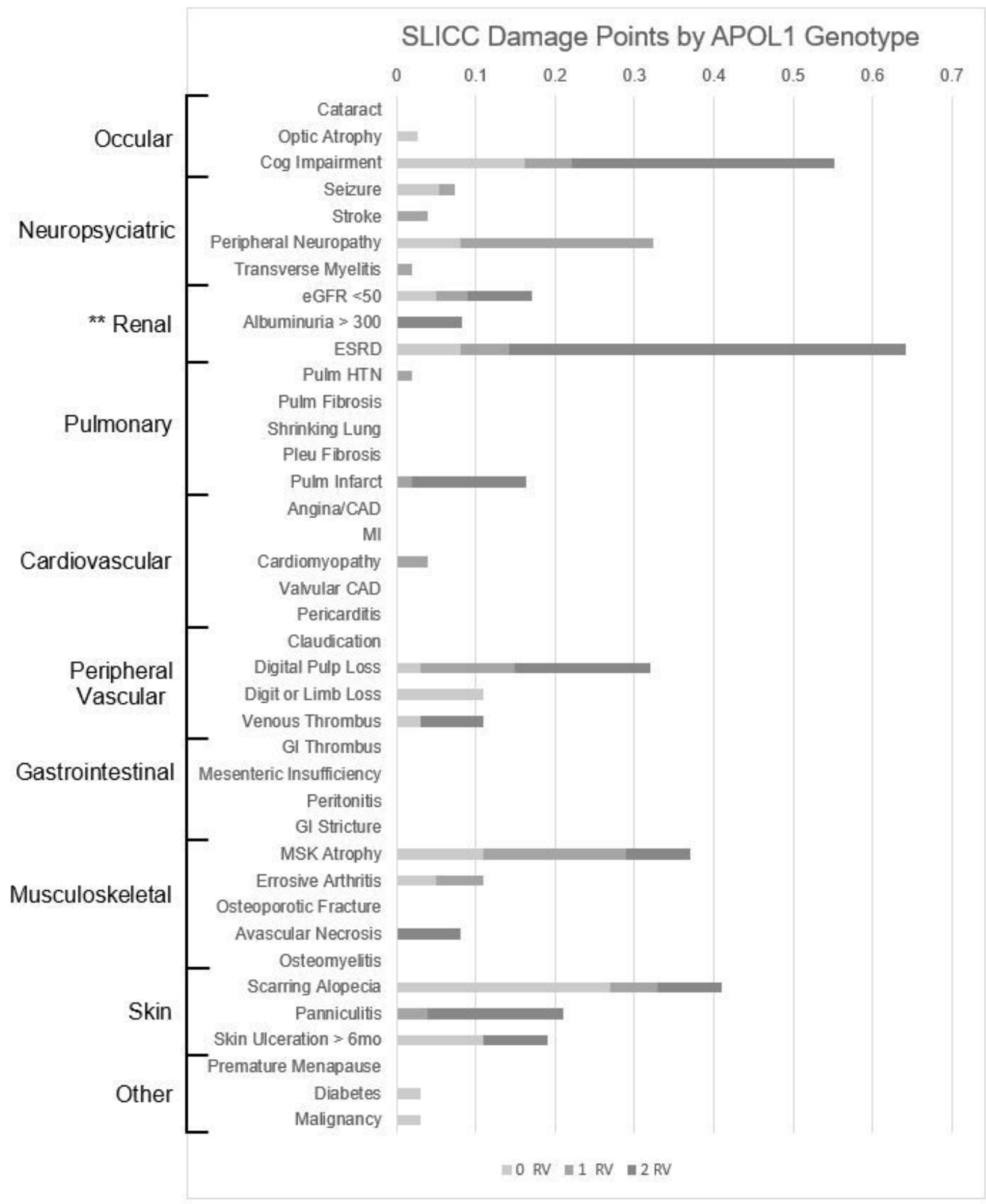

\section{Figure 1}

SLICC Damage Index Across APOL1 Genotype: Stacked bar chart visualizing the mean SLICC damage index (SDI) points accrued by genotype group (ORV in blue, 1RV in orange, 2RV in gray). Each damage criterion is ordered by affected organ system (shown to the left). 
A.

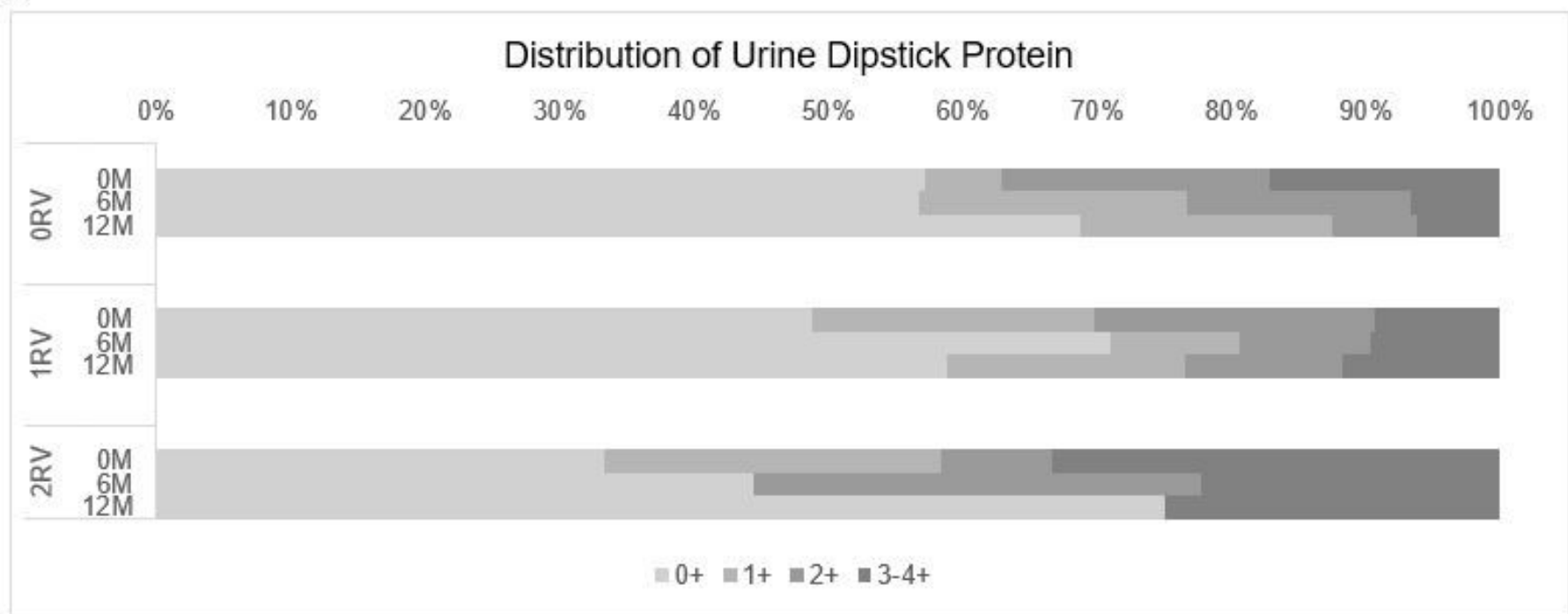

B.

Mean Arterial Pressure by APOL1 Genotype and Timepoint

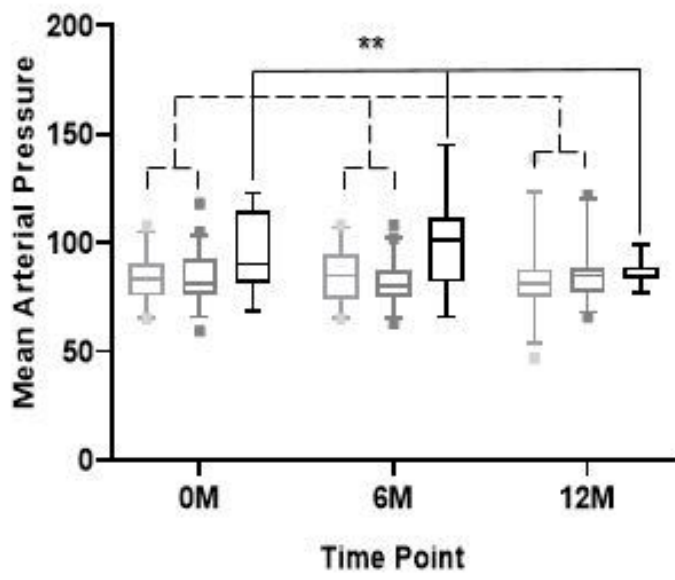

C. eGFR by APOL1 Genotype and Timepoint
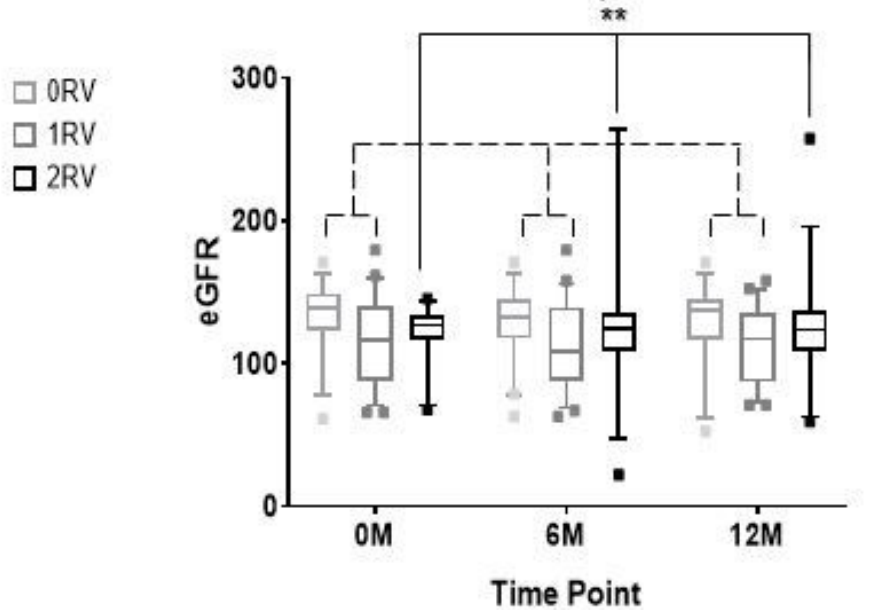

Figure 2

Distribution of Kidney Function Parameters by APOL1 Genotype and Timepoint: A. The bars represent the proportion of patients in each urine dipstick range (0+-3-4+). The $X$ axis represents percentages, and the $Y$ axis represents the genotype groups by time point $(0 \mathrm{M}=$ month zero, $6 \mathrm{M}=$ month $6,12 \mathrm{M}=$ month 12$)$. At each timepoint the proportion of patients in the higher dipstick propteinuria ranges was higher in the 2RV patients. These differences did not reach statistical significance. B. The boxplots represent the distribution of mean arterial pressure $(\mathrm{mmHg})$ values by genotype groups and time point. Overall, $2 \mathrm{RV}$ patients exhibited significantly higher mean arterial pressure values $(p=0.01)$. C. The boxplots represent the distribution of mean eGFR $(\mathrm{mL} / \mathrm{min})$ values by genotype groups and time point. Overall, $2 \mathrm{RV}$ patients exhibited significantly lower mean arterial pressure values $(p=0.01)$. $P=0.01$ is indicated by **. 
A.

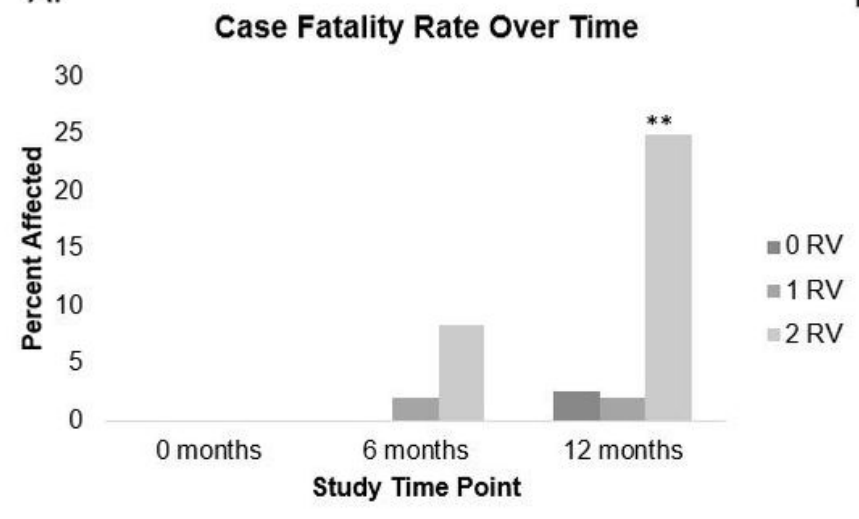

B.

\begin{tabular}{|c|c|c|c|c|}
\hline & & 0 months & 6 months & 12 months \\
\hline \multirow{3}{*}{$\begin{array}{l}\text { Causes } \\
\text { of } \\
\text { Death }\end{array}$} & $\begin{array}{c}0 \\
\text { RV }\end{array}$ & & & 1. ESRD \\
\hline & $\begin{array}{c}1 \\
\mathrm{RV}\end{array}$ & & $\begin{array}{l}\text { 1. Sepsis during } \\
\text { pregnancy }\end{array}$ & \\
\hline & $\begin{array}{c}2 \\
\text { RV }\end{array}$ & & $\begin{array}{l}\text { 2. Heart } \\
\text { Failure/Pulm } \\
\text { edema }\end{array}$ & $\begin{array}{ll}\text { 2. } & \text { ESRD } \\
\text { 3. Unknown } \\
\text { (ESRD at } \\
\text { death) }\end{array}$ \\
\hline
\end{tabular}

\section{Figure 3}

Case Fatality Rate by APOL1 Genotype: A. Bars represent each genotype group (ORV, 1RV, or 2RV). The Y axis represents the percentage of patients in that genotype group who died, and the $X$ axis shows the study time point. ** represents $p<0.01 \mathrm{~B}$. Table represents the causes of death at each time point by genotype group. $\mathrm{ESRD}=$ End stage renal disease; Pulm = pulmonary . 